\title{
Herd Behavior and Its Effects on Default in Chinese Microcredit
}

\author{
Ya Bu $\mathbb{D}^{1},{ }^{1}$ Shouzhe Zhang $\mathbb{D},{ }^{2}$ and Anzhong Huang $\mathbb{D}^{1}$ \\ ${ }^{1}$ School of Economics and Management, Jiangsu University of Science and Technology, Zhenjiang 212100, China \\ ${ }^{2}$ School of Economics and Management, Chuzhou University, Chuzhou 239000, China \\ Correspondence should be addressed to Shouzhe Zhang; zsz@chzu.edu.cn
}

Received 13 May 2021; Accepted 2 August 2021; Published 24 August 2021

Academic Editor: Shaohui Wang

Copyright (C) $2021 \mathrm{Ya} \mathrm{Bu}$ et al. This is an open access article distributed under the Creative Commons Attribution License, which permits unrestricted use, distribution, and reproduction in any medium, provided the original work is properly cited.

Herd behavior means a mode of behavior will be infected among the individuals in a group, and its existence and influence in specific financial market are uncertain. The paper utilizes the logistic model to test the existence and influence of herd behavior of borrowers in Chinese microcredit market. We find that (1) herd behavior exists in Chinese microcredit market, (2) the two most important factors affecting the default of microcredit resulted from herd behavior are the nature of microcredit institutions and the education level of borrowers, and (3) herd behavior will increase the possibility of default, but it is relatively small.

\section{Introduction}

Herd behavior means a mode of behavior which will be infected among the individuals in a group, that is to say, the individuals in a group will think and act like most people. As for the influence of herd behavior in financial markets, Jegadeesh and Kim [1] regarded that herd behavior would aggravate market volatility, undermine market stability, and further increase the fragility of the financial system. So, herd behavior is the trigger of financial crisis. At present, the academic community has mainly focused on the three aspects of influence of herd behavior in the financial market.

First is the influence of herd behavior on the stock market. This kind of research mainly studies the risk of stock price fluctuation and stock price collapse which resulted from herd behavior (e.g., [2]). Second is the influence of herd behavior on commodity market. This kind of research focuses on the existence or the influence on the commodity market (e.g., $[3,4])$. Third is the influence of herd behavior on Internet finance. This kind of research mainly takes the peer-to-peer lending as the research object and regards the herd behavior which will result in higher risk of default (e.g., [5]).

However, we find that there are few scholars who have carried out research studies on the influence of herd behavior on the credit market. In view of this, this paper takes Chinese microcredit as the research object to explore the existence of herd behavior of borrowers and its effects on default. The reason for choosing microcredit as the most research object is that microcredit is the most important tool assigned by the World Bank to help to construct inclusive finance and alleviate poverty. Therefore, studying the impact of herd behavior on microcredit will help developing countries to achieve poverty alleviation goals.

\section{Testing the Existence of Herd Behavior}

2.1. Method. Because the data availability of the LSV method is stronger and easier to implement, it is widely used in academic circles to test the existence of herding behavior. This paper adopts the modified LSV method by Wermers [6]. The method has three specific dimensions: first, the herd behavior is measured by the time interval of applying for loan. With the times of application increasing, the time interval between applications will shorten, which is used to demonstrate the existence of herd behavior (e.g., [7]). The second is to test whether the market share increases with time, which is used to demonstrate the existence of herd behavior (e.g., Lee) and [5]. The third is to use "Whether to Get Subsequent Loan" as the dependent variable to test herd behavior (e.g., [8]).

The quality of date must be high in measuring the existence of herd behavior, no matter through testing time interval or testing market share. Therefore, this paper 
chooses "Whether to Get Subsequent Loan" as the dependent variable and "the Times of Current Loan" as the independent variable. The null hypothesis is that if the dependent variable is significantly and positively influenced by the independent variable, there is herd behavior in microcredit market; otherwise, there is no herd behavior.

2.2. Variables and Econometric Model. According to the characteristics of Chinese microcredit market, the paper selects 15 control variables. The detailed descriptions of the names, codes, and definitions of the variables are shown in Table 1.

According to the selected variables, the corresponding logistic regression model is

$$
\begin{aligned}
\ln \left(\frac{P}{1-P}\right)= & \beta_{0}+\beta_{1} \mathrm{TCL}+\beta_{2} \mathrm{LA}+\beta_{3} \mathrm{LR}+\beta_{4} \mathrm{LL} \\
& +\beta_{5} \mathrm{NMI}+\beta_{6} \mathrm{OTD}++\beta_{7} G+\beta_{8} A+\beta_{9} \mathrm{EL} \\
& +\beta_{10} \mathrm{FL}+\beta_{11} \mathrm{SLT}+\beta_{12} \mathrm{NRT}+\beta_{13} \mathrm{ALA} \\
& +\beta_{14} \mathrm{PA}+\beta_{15} \mathrm{TNB}+\beta_{16} \mathrm{BD}+\varepsilon .
\end{aligned}
$$

$P=1$ means the current loan will get subsequent loan, while $P=0$ means no subsequent loan.

2.3. Data Resource. The selected sample period is from the first quarter of 2013 to the fourth quarter of 2017. The data of independent variables and control variables are provided by China Association of Microcredit. The preliminary empirical results show that the value of sig. in the Hoster and Lemeshow tests is obviously less than 0.05 . It implies that the model is not good in fitting the original data as a whole. Moreover, many variables do not pass the significance test. Therefore, in order to ensure the reliability of the empirical results, the common processing methods are stepwise regression and factor analysis. The common factor was formed by analysis, and then, the same common factor was used as an independent variable for logistic regression analysis.

2.4. Results of the Factor Analysis. Firstly, the KMO and Bartlett Test of Sphericity is carried out on the variables that affect dependent variables. According to the results in Table 2 , the KMO statistic value is 0.698 , which is greater than the standard value of 0.5 , so the factor analysis can be performed. The approximate chi-square value is 240121.092 and the sig. value is 0.001 . It can be seen that the spherical hypothesis is rejected and there is a strong correlation among variables, so it is appropriate to carry out factor analysis.

The common factor was extracted by principal component analysis. The test results in Table 3 indicate that 5 common factors meet the requirements when setting factors with extraction feature values greater than 1 . At the same time, the results show that the cumulative contribution rate of these 5 factors reaches $83.83 \%$, which has good explanatory power.

The factor loading matrix indicates that all selected factors have linear relationship with original variables, while the rotated factor has a high load, which can simplify the explanation of the factor and is more beneficial to the explanation of various factors. According to the rotated component matrix, all the common factors $\left(F_{i}\right)$, respectively, include the variables: the first $\left(F_{1}\right):$ LL, ALA, and PA; the second $\left(F_{2}\right):$ LA, $A$, and FLN; the third $\left(F_{3}\right): L R, G$, and TNB; the fourth $\left(F_{4}\right)$ : TCL, NMI, EL, and BD; the fifth $\left(F_{5}\right)$ : OTD, SLT, and NRT.

2.5. Results of Logistic Regression. Taking the common factor as the independent variable, the modified logistic model is

$$
\ln \left(\frac{P}{1-P}\right)=\beta_{0}+\beta_{1} F_{1}+\beta_{2} F_{2}+\beta_{3} F_{3}+\beta_{4} F_{4}+\beta_{5} F_{5}+\varepsilon .
$$

The results of comprehensive test of coefficients shown in Table 4 indicate that the likelihood of the model is very larger than the chi-square value, and the $p$ value is 0 , which shows that the equation has stronger significance. The summary of the model shows that the $-2 \log$ likelihood value is larger than the chi-square critical value in the table above and indicates that the model fits well. In addition, the $p$ value of Hosmer and Lemeshow test is significantly greater than 0.05 , which indicates that there is no sufficient reason to reject the null hypothesis. There is a significant difference between the predicted and observed values of the model, which suggests that the overall fitting effect of the model is good.

The results in Table 5 indicate that the $p$ values of first and fifth common factors are greater than 0.05 and others are smaller than 0.05 , which suggest that the coefficients of the model have good significance and their influences are positive. In particular, the coefficient of the fourth common factor is much higher than other common factors, which suggests that the TCL, NMI, EL, and ELBD are the reasonable explanatory variables. The significant positive influence also shows that, with the increase of the current times of application, the subsequent borrowing will also increase. Therefore, it is verified that there is obvious herd behavior in Chinese microcredit market.

\section{Effects of Herd Behavior on Default}

3.1. Method. Since it is not possible to directly obtain the time when the borrower defaults and the information provided by the Microcredit Alliance related to defaults is only the number of times the borrower defaults, so the logistic default model is the most appropriate selection. Since the influence of the first and fifth common factors is not significant, we will eliminate the variables contained in the first and fifth common factors. The revised default model is as follows: 
TABle 1: Meanings, codes, and definition of the variables.

\begin{tabular}{|c|c|c|}
\hline & Names of variable (code) & Definition \\
\hline \multirow{2}{*}{$\begin{array}{l}\text { Dependent variable } \\
\text { Independent } \\
\text { variable }\end{array}$} & \multirow{2}{*}{$\begin{array}{l}\text { Whether to get subsequent loan } \\
\text { The current times of application } \\
\text { (TCL) }\end{array}$} & If there is subsequent loan, the value is 1 , otherwise, 0 \\
\hline & & The times of application for microcredit \\
\hline \multirow{15}{*}{ Control variables } & Loan amount (LA) & The amount of current application \\
\hline & Loan interest (LR) & The interest rate of the microcredit \\
\hline & Life of loan (LL) & The life of the microcredit to be granted \\
\hline & $\begin{array}{l}\text { Nature of microcredit } \\
\text { institutions (NMI) }\end{array}$ & If the microcredit institutions are government led, the value is 1 , otherwise, \\
\hline & Original times of default (OTD) & The total numbers of failing to repay on time \\
\hline & Gender $(G)$ & The borrowers are male, the value is 1 , female, 0 \\
\hline & Age $(A)$ & The ages of borrowers \\
\hline & Education level (EL) & Bachelor degree or above, the value is 1 , below, 0 \\
\hline & First lending or not (FLN) & If it is first loan, the value is 1 , otherwise, 0 \\
\hline & The successful loan times (SLT) & The successful loan times by now \\
\hline & Normal repayment times (NRT) & Normal repayment times by now \\
\hline & Accumulated loan amount (ALA) & The accumulated amount of loan by now \\
\hline & The prepared amount (PA) & The prepared amount of repayment \\
\hline & Total number of borrowing (TNB) & Total number of borrowing by now \\
\hline & Proportion of bad debt (BD) & Proportion of bad debt of total loan \\
\hline
\end{tabular}

TABLe 2: Results of KMO and Bartlett tests.

\begin{tabular}{lcc}
\hline & Kaiser-Meyer-Olkin measure of sampling adequacy & 0.698 \\
\hline & Approximate chi square & 240121.092 \\
Bartlett test of sphericity & D f & 149 \\
& Sig & 0.001 \\
\hline
\end{tabular}

TABLE 3: The interpreted total variance.

\begin{tabular}{|c|c|c|c|c|c|c|c|c|c|}
\hline \multirow{2}{*}{ Common factors } & \multicolumn{3}{|c|}{ Initial eigenvalue } & \multicolumn{3}{|c|}{ Sum of squares extracted } & \multicolumn{3}{|c|}{ Sum of squares rotated } \\
\hline & Total & Var. (\%) & Cumulative sum (\%) & Total & Var. (\%) & Cumulative sum (\%) & Total & Var. (\%) & Cumulative sum (\%) \\
\hline 1 & 3.12 & 23.20 & 23.20 & 3.52 & 21.87 & 21.87 & 3.05 & 21.06 & 21.06 \\
\hline 2 & 2.36 & 19.01 & 42.21 & 3.01 & 19.11 & 40.98 & 2.65 & 17.30 & 38.36 \\
\hline 3 & 1.83 & 16.33 & 58.54 & 2.85 & 17.63 & 58.61 & 2.14 & 16.48 & 54.83 \\
\hline 4 & 1.49 & 14.25 & 72.80 & 1.90 & 15.20 & 73.81 & 1.68 & 15.24 & 70.07 \\
\hline 5 & 1.01 & 11.04 & 83.83 & 1.53 & 10.02 & 83.83 & 1.21 & 13.76 & 83.83 \\
\hline
\end{tabular}

TABLE 4: Results of logistic regression analysis.

\begin{tabular}{cccccccc}
\hline & \multicolumn{4}{c}{ Comprehensive test of coefficients } & \multicolumn{2}{c}{ Summary of model } \\
& & Chi square & $\mathrm{d} f$ & Sig & -2 log likelihood & Cox and snell $R$ square & Nagelkerke $R$ square \\
\hline \multirow{3}{*}{ Step 1 } & Step & 513.297 & 5 & 0.001 & 1743.170 & 0.179 & 0.301 \\
& Bloc & 513.297 & 5 & 0.001 & & Results of Hosmer and Lemeshow test & 0.202 \\
\hline
\end{tabular}

TABle 5: Details of common factor.

\begin{tabular}{cccccccc}
\hline & & $B$ & W.E. & Wals & df & Sig. & Exp $(B)$ \\
\hline \multirow{4}{*}{ Step 1 } & FAC1 & -0.096 & 0.061 & 0.964 & 1 & 0.632 & 0.952 \\
& FAC2 & 0.094 & 0.088 & 51.086 & 1 & $0.000^{* * *}$ & 2.543 \\
& FAC3 & 0.215 & 0.072 & 37.209 & 1 & $0.021^{*}$ & 1.209 \\
& FAC4 & 1.203 & 0.109 & 241.753 & 1 & $0.000^{* * *}$ & 6.071 \\
& FAC5 & -0.102 & 0.057 & 1.002 & 1 & 0.749 & 0.970 \\
& Constant & - & 0.091 & 233.762 & 1 & $0.000^{* * *}$ & 5.437 \\
\hline
\end{tabular}

Note: ${ }^{*},{ }^{* *}$, and ${ }^{* * *}$ denote the $10 \%, 5 \%$, and $1 \%$ significant level, respectively. 


$$
\begin{aligned}
\ln \left(\frac{Y}{1-Y}\right)= & \beta_{0}+\beta_{1} \mathrm{TCL}+\beta_{2} \mathrm{LA}+\beta_{3} \mathrm{LR}+\beta_{5} \mathrm{NMI} \\
& +\beta_{6} \mathrm{OTD}+\beta_{7} G+\beta_{8} A \\
& +\beta_{9} \mathrm{EL}+\beta_{10} \mathrm{FL}+\beta_{15} \mathrm{TNB}+\beta_{16} \mathrm{BD} .
\end{aligned}
$$

$Y=1$ means the borrower will default, while $Y=0$ means no default.

3.2. Results. The results in Table 6 indicate that the value $p$ is significantly less than 0.05 , which suggests that the comprehensive test of model coefficients has passed. The value of -2 log likelihood is also greater than the previous chi-square critical value, so the model fits well as a whole. In addition, the $p$ value of Hosmer and Lemeshow tests is also greater than 0.05 , which shows that the overall goodness of fit of the model is high.

The results in Table 7 suggest that the value of $p$ is smaller than 0.05 and the coefficient is negative, which indicate that the bigger the value of TCL, the less the possibility of default. Theoretically, the herd behavior of borrowers in Chinese microcredit market can reduce the possibility of default. However, because the absolute value of its coefficient is very small, its actual impact on the possibility of default is also very small, which suggests that the borrower's behavior is rational to some extent. When most borrowers can do this, the market will automatically eliminate those borrowers with high risk of default, thus reducing the risk of default in the entire market. Therefore, herd behavior in China microcredit market can reduce the possibility of default.

The borrower's ability also affects the possibility of default. There is a positive correlation between $\mathrm{BD}$ and the possibility of default. When a borrower has strong investment ability, he or she will choose the loan with lower default probability and exclude the target with higher default probability, thus reducing the probability of default. Another indicator of investor's ability TNB is negatively correlated with default. This also shows that the more experienced the borrowers are, the more they can choose the target with less possible default.

At the same time, EL is positively related to the probability of default, which means that the higher the value of EL, the higher the probability of default. This may be due to the fact that borrowers understand the characteristics of investors' preference for highly educated, so low-educated borrowers pay more attention to the default. The nature of microcredit institutions has a significant impact on defaults. The government-led microcredit has higher possibility of default, while the nongovernment-led microcredit institutions are relatively lower.

\section{Discussion}

From the findings, we learn that herd behavior exists among borrowers of Chinese microcredit and that herd behavior has an impact on default, but it is not significant.
Generally, the applicants of microcredit are mainly small business owners and the poor, and they have the characteristics of large population and residential dispersion, so the cost of accessing information about them is higher, which is the most important factor resulting herd behavior. In addition, conformity psychology, trading mechanism, as well as some factors of microcredit itself, etc., are the factors resulting herd behavior too. However, the two most important factors with Chinese characteristics are the nature of microcredit institutions and the education level of borrowers.

The Chinese government has long implemented the poverty alleviation policy through free financial subsidies. Meanwhile, besides government-led type, Chinese microcredit institutions also include banking, $P 2 P$, Fintech companies, etc., among which only government-led microcredit institutions are public ownership. So, the borrowers, whose education levels are lower, whose decisionmaking capacities are limited and prefer to conformity behavior, mistakenly believe that the government-led microcredit is also similar to the free financial subsidies. Therefore, herd behavior is significant among them. And, more importantly, the funds of government-led microcredit come from the government's finance, and public ownership means the property rights are not clear. So, when the borrower defaults, the government has no corresponding measures even credit rating. On the contrary, the funds of other types come from market financing with clear property rights. So, when the borrower defaults, the institution will take various measures or even resort to violence to recover the loan. Therefore, the default cost of the government-led microcredit is very low, which leads herd behavior of borrowers to be more serious.

Since the market share of government-led microcredit is limited, when we take Chinese microcredit as a whole, we find that herd behavior has no serious impact on default. We surmise that even if there are serious impacts of herd behavior on default of government-led microcredit, it may be diluted. Whether it is the case or not, the article does not have a definite answer. In addition, this article takes microcredit as a whole, and it is unable to answer some specific questions. Therefore, we believe that future research studies can take into consideration the differences of herd behavior in gender, age, region, etc.

In order to utilize microcredit to achieve poverty alleviation more effectively, the paper proposes the following.

First, utilize the positive role of the herd behavior in the microcredit market. Although the empirical results show that the herd behavior is rational to some extent and can reduce the overall loan default, the impact is very small. Therefore, it is very important to expand this positive influence, which can be practiced from two aspects. On the one hand, it can reduce the occurrence of irrational herd behavior of investors; on the other hand, it can strengthen the leading role of key borrowers in the group.

Second, build a credit rating system and playing the role of market supervision. Herd behavior in Chinese microcredit market and its negative impact on default are partly due to the nonself-discipline of borrowers, such as the 
TABLE 6: Results of logistic regression analysis.

\begin{tabular}{ccccccccc}
\hline & \multicolumn{4}{c}{ Comprehensive test of coefficients } & \multicolumn{2}{c}{ Summary of model } \\
& & Chi square & $\mathrm{d} f$ & Sig & $-2 \log$ likelihood & Cox and snell $R$ square & Nagelkerke $R$ square \\
\hline \multirow{3}{*}{ Step 1 } & Step & 257.438 & 12 & 0.001 & 1550.232 & 0.120 & 0.203 \\
& Bloc & 257.438 & 12 & 0.001 & & Results of Hosmer and Lemeshow tests & 0.068 \\
\hline
\end{tabular}

TABLE 7: Variables in the model.

\begin{tabular}{cccccccc}
\hline & & $B$ & S.E. & Wals & d $f$ & Sig & $\operatorname{Exp}(B)$ \\
\hline \multirow{4}{*}{ Step 1 } & TCL & 0.005 & 0.001 & 24.250 & 1 & $0.001^{* * *}$ & 1.000 \\
& NMI & 0.254 & 0.000 & 33.542 & 1 & $0.001^{* * *}$ & 1.076 \\
& EL & 0.107 & 0.094 & 15.209 & 1 & $0.019^{* *}$ & 0.968 \\
& TNB & 0.034 & 0.086 & 13.095 & 1 & $0.023^{* *}$ & 0.953 \\
\hline
\end{tabular}

Note: the paper only lists the factors whose influence is significant.

influences of government-led microcredit and educational level. Therefore, the market should establish a credit rating system and use the reputation restraint mechanism to promote self-discipline of borrowers.

Third, strengthen government supervision. The operation status of the platform also affects investors' herding behavior. If the platform operation mechanism is not complete, even if investors can make rational herding behavior, it may also cause negative impacts. However, the domestic platform operation mechanism is quite different, which also leads to the conclusion that the herding behavior in the auction and loan studied in this paper is not completely consistent with the conclusion of other scholars. Therefore, strengthening the classified supervision of different platforms and the supervision of prominent problems on platforms can strengthen the positive role of rational investor herding behavior.

\section{Data Availability}

The data are provided by China Association of Micro-Credit. http://chinamfi.net/.

\section{Conflicts of Interest}

The authors declare that they have no conflicts of interest.

\section{Acknowledgments}

The research was one of midterm results of major research project of philosophy and social science in universities of Jiangsu Province "Research on the Optimization of the Regulatory PATH of TinTech Innovations" (2019SJZDA060), humanities and social science project prepared for universities and colleges by Anhui Education Bureaus, called "Researches on the route of promoting the industrialization of ecological agriculture in Anhui Province by Fintech (SK2018A0418)," as well as the Humanities and Social Sciences Project of the Ministry of Education of the PRC "Research on the Formation Mechanism of Microfinance Poverty Alleviation and Innovation of Jiangsu Practice Model" (20YJA790028).

\section{References}

[1] N. Jegadeesh and W. Kim, "Do analysts herd? An analysis of recommendations and market reactions," Review of Financial Studies, vol. 23, no. 2, pp. 901-937, 2009.

[2] X. Nianxing, Y. Shangyao, and Y. Zhihong, "Herd behavior of institutional investors and risk of stock price collapse," Management World, vol. 7, pp. 31-43, 2013.

[3] S. Ke and J. Huang, "Research on the herd behavior of Chinese real estate market based on non-linear test model CSAD," Management Reviews, vol. 24, no. 9, pp. 19-25, 2012.

[4] X. Liu, G. Filler, and M. Odening, "Testing for speculative bubbles in agricultural commodity prices: a regime switching approach," Agricultural Finance Review, vol. 73, no. 1, pp. 179-200, 2013.

[5] X. Lin, X. Li and Z. Zheng, Evaluating borrower's default risk in peer-to-peer lending: evidence from a lending platform in China," Applied Economics, vol. 49, no. 35, pp. 1-8, 2016.

[6] R. Wermers, "Mutual fund herding and the impact on stock prices," The Journal of Finance, vol. 54, no. 2, pp. 581-622, 1999.

[7] B. Luo and Z. Lin, "A decision tree model for herd behavior and empirical evidence from the online P2P lending market," Information Systems and E-Business Management, vol. 11, no. 1, pp. 141-160, 2013.

[8] M. Herzenstein, U. M. Dholakia, and R. L. Andrews, "Strategic herding behavior in peer-to-peer loan auctions," Journal of Interactive Marketing, vol. 25, no. 1, pp. 27-36, 2011. 